\title{
World Journal of Laparoscopic approach for intermittent
Pediatric Surgery hydronephrosis caused by primary ureteral fibroepithelial polyps in children
}

\author{
Han Chu, Yongsheng Cao, Qifei Deng
}

To cite: Chu H, Cao Y, Deng Q. Laparoscopic approach for intermittent hydronephrosis caused by primary ureteral fibroepithelial polyps in children. World Jnl Ped Surgery 2021;4:e000243. doi:10.1136/ wjps-2020-000243

- Additional material is published
online only. To view, please visit the journal online (http://dx.doi. org/10.1136/wjps-2020-000243)

Received 21 November 2020 Revised 23 February 2021 Accepted 24 February 2021

Check for updates

(C) Author(s) (or their employer(s)) 2021. Re-use permitted under CC BY-NC. No commercial re-use. See rights and permissions. Published by BMJ.

Urology (II), Anhui Provincial Children's Hospital, Hefei, Anhui, China

Correspondence to Dr Han Chu; love5217758@ 126.com

\section{ABSTRACT}

Objective To summarize the diagnosis and treatment experience of children with intermittent hydronephrosis caused by ureteral fibroepithelial polyp (UFP).

Methods From 2017 to 2020, cases of hydronephrosis caused by ureteral polyp in Anhui Provincial Children's Hospital were retrospectively enrolled for investigation. Demographic data, clinical manifestations, operation details, pathology and outcomes were collected from patients' medical data for analysis.

Results All seven cases of UFP were boys, including six cases on the left side of the ureter and one case on the right side, at the median age of 7.1 years (3-14 years), with abdominal intermittent pain as the first symptom. All cases underwent laparoscopic pyeloureteroplasty. All the operations were completed successfully; postoperative pathology indicated the presence of primary UFP. Postoperative follow-ups of 1-30 months showed satisfactory recovery and relief from hydronephrosis.

Conclusions Laparoscopic pyeloureteroplasty or ureteroureterostomy is one of the optimal treatments for ureteral polyp at present. The surgical method should be determined according to the number of polyps, the length and the diameter of the affected ureter, and also the status of renal function of the patients.

\section{INTRODUCTION}

Primary ureteral fibroepithelial polyps (UFPs) are mostly benign lesions of the urinary tract. Non-epithelial tumors of mesodermal origin are derived from the mesenchymal tissue instead of the epithelium and account for $20 \%$ of all ureteral tumors. ${ }^{1}$ In the upper urinary tract, UFPs were thought to be rare, consisting of only $0.5 \%$ of all causes of ureteropelvic junction obstruction (UPJO) in the pediatric population. ${ }^{2}$ Bilateral incidence is low. ${ }^{3}$ The etiology of ureteral polyps is not clear. There are various factors such as genetic factors, irritability, infection, hormone and trauma. ${ }^{4}$ UFPs may contribute to UPJO and may result in intermittent hydronephrosis in children. It is difficult to diagnose precisely before operation. Recent studies have shown that as low as $5 \%-22 \%$ of UFPs could be diagnosed without surgery. ${ }^{5}$ To better diagnose and treat UFPs in children, pathologically proven cases
Key messages

What is already known about this subject?

- It is a kind of reason that ureteral fibroepithelial polyp (UFP) causes intermittent hydronephrosis.

- This kind of hydronephrosis usually appeared as the clinical manifestation of renal colic.

- The hydronephrosis disappeared as symptoms disappeared.

- Ureteroscopy may be a good preoperative diagnostic method.

What are the new findings?

- It is a good choice to diagnose and treat single polyps with ureteroscopy.

- Laparoscopic pyeloureteroplasty is a mature surgical method for hydronephrosis caused by UFPs (the length of the polyp segment ureter is $<5 \mathrm{~cm}$ ).

- If the length of the ureter with polyp segment is $\geq 5 \mathrm{~cm}$, replacement of the ureter with the ileum or appendix is a good choice.

How might it impact on clinical practice in the foreseeable future?

- This article could provide us with a reasonable diagnosis and treatment of intermittent hydronephrosis in the future. If we doubt a child with intermittent hydronephrosis caused by UFPs, we can give him a proper treatment by this article.

between 2017 and 2020 were reviewed in the Urology Department (II), Anhui Provincial Children's Hospital. All cases in the series had undergone laparoscopic surgery and achieved favorable outcomes according to postoperative follow-up.

\section{METHODS}

With the approval by the institutional review board of our hospital (online supplemental file 1), a retrospective chart review of pediatric patients who underwent laparoscopic pyeloplasty between 2017 and 2020 in our department was conducted. Patients diagnosed as UFPs were enrolled for analysis.

The demographic data, clinical symptoms, preoperation findings, operation details, 
pathology, postoperation complications and outcomes in follow-up were collected from medical records with the approval of patients' parents. The data were listed as median (range) or listed in tables.

Patients underwent a transperitoneal, three-port laparoscopic approach to resect the ureteral lesion segment. Preoperative catheters were placed, and the affected side was elevated. The left side of the lesion was taken through the mesentery, and the right side was taken through the lateral colon to expose the ureteropelvic junction (UPJ), freeing the ureter along the UPJ, and the ureteral lesion was exposed. The longitudinal incision on the inside of ureter was made to investigate the length of polyp encroachment in the ureter. According to the length of the lesion ureter, the renal pelvis and ureter were freed adequately. Under the premise of no tension on the anastomosis, the segment of lesion ureter was got rid of until the normal ureter without polyp was seen. Lengthwise incision of about $1-1.5 \mathrm{~cm}$ was made at the outside lateral edge of the normal ureter. The renal pelvis should be trimmed to facilitate the anastomosis without tension. Ureteropelvic anastomosis was then performed. Before the suture was completed, through the anastomotic stoma, F4 double $\mathrm{J}$ was placed into the ureter, and an F10 abdominal cavity drainage tube was reserved at last. An abdominal drainage tube, a catheter and a double "J" were put in the affected side of the ureter in all patients. Each resected specimen was subjected to a pathological examination.

\section{RESULTS}

Seven cases of UFPs were enrolled in the study. All of them were boys, including six cases on the left side and one case on the right side; the median age was 7.1 years (3-14 years), with abdominal intermittent pain as the first symptom, accompanied by nausea and vomiting. None of them had gross hematuria and bacteriuria. Two of them had microscopic hematuria. Ultrasonography and urinary tract computed tomography (CT) showed varying degrees of hydronephrosis in these cases, which were associated with symptom onset. However, both methods failed to identify the ureteral polyps. Five patients' intravenous pyelography (IVP) images showed potential UPJO. Only two cases were highly suggestive of UFP preoperation, which showed the typical "earthworm shape" X signs and filling defects in IVP (figure 1). Children with UPJO might merge vesicoureteral reflux (VUR), so voiding cystourethrography (VCU) examination was checked preoperatively in all cases and results were normal. A common feature of all the examinations was that the degree of hydronephrosis decreased with pain relief in the children.

Laparoscopic surgery was successfully completed on all patients. UPJ was located in three cases, and the upper ureter segment was located in four cases. The mean operating time was 204.4 minutes (146-287minutes), and no perioperative complications were encountered.

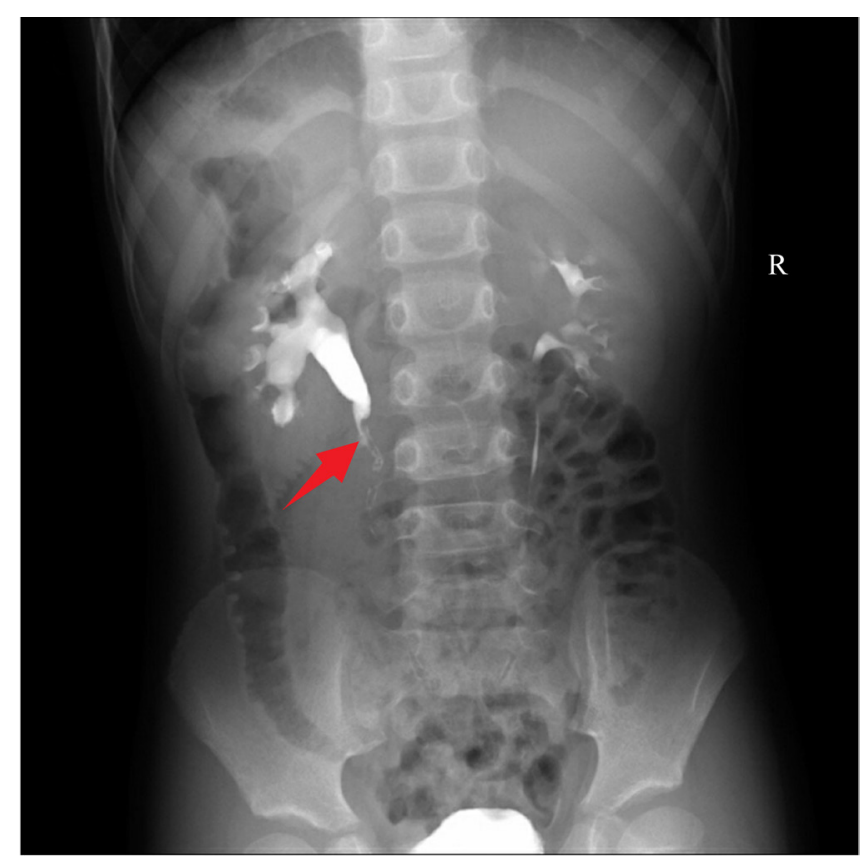

Figure 1 Findings of ureteral fibroepithelial polyps on intravenous pyelography. The defect in the ureter showed the location of the polyps (red arrow). $\mathrm{R}$, right.

Intestinal function was restored within 48 hours after surgery. Urethral catheters and abdominal drainage tubes were removed in 3-5 days after surgery, and double "J" tube was removed 1 month after surgery.

The longest segment of ureteral polyps in the 7 children was $3 \mathrm{~cm}$ (table 1), and renal pelvis and ureter could be anastomosed without tension after full release in all cases. We found a single polyp (figure 2A), multiple polyps (figure 2B) and wide-base polyps resembling "octopus tentacles" (figure 2C) in the operations. Postoperative pathology confirmed primary UFPs in seven cases (figure 3), with one case accompanied by the lesions of intrinsic UPJ. The characteristics of UFPs in the seven children are displayed in table 1.

Follow-ups were conducted in 1, 3, and 6 months and $1.0,1.5$, and 2.0 years after surgery. Ultrasound and IVP examinations were performed in 1 and 2 years after operation with favorable results on a short view (three cases did not undergone IVP for being in less than half a year after operation). No additional symptoms, such as low back pain and abdominal pain, were found among the children.

\section{DISCUSSION}

Approximately $62 \%$ of UFPs occur at the UPJ and the upper ureter. UFPs are more commonly found in boys (usually older boys) and especially predominant on the left side of the ureter. ${ }^{6}$ Ureteral polyp is one of the causes of endogenous intermittent hydronephrosis, which consists of mesodermal and normal transitional epithelial cells, and it can cause intermittent hydronephrosis, which was first described by Nesbit (1956) in patients who were having acute attacks of pain but whose pyelograms were 
Table 1 Characteristics of ureteral fibroepithelial polyps

\begin{tabular}{lllll}
\hline Age $(\mathbf{y})$ & Side & Location & Type of polyps (length of poly) & Length of lesion ureter $(\mathbf{c m})$ \\
\hline 7 & Left & UPJ & Two single $(0.7$ and $0.8 \mathrm{~cm})$ & 2 \\
\hline 4 & Left & Upper ureter & Multiple, wide base & 2.5 \\
\hline 9 & Right & UPJ & One single $(1 \mathrm{~cm})$ & 1.5 \\
\hline 7 & Left & Upper ureter & Multiple, wide base & 2.2 \\
\hline 14 & Left & Upper ureter & Four single $(1.0,1.2,1.4$ and $1.5 \mathrm{~cm})$ & 1.5 \\
6 & Left & UPJ & Two single $(3.5$ and $1.1 \mathrm{~cm})$ & 2 \\
\hline 3 & Left & Upper ureter & One single $(0.3 \mathrm{~cm})$, wide base & 3 \\
\hline
\end{tabular}

UPJ, ureteropelvic junction.

normal between attacks. ${ }^{7}$ When ureteral polyp causes ureteral obstruction, it will result in the clinical symptoms of renal colic, like abdominal pain accompanied by nausea and vomiting. These symptoms generally resolve spontaneously and are followed by a pain-free interval that ranges from days to months. Therefore, in such children, we need to exclude the possibility of ureteral calculi, and a biopsy should be performed when intraoperative malignancy is suspected. When ureteral polyp epidermis is erosive and inflamed, hematuria appears; it is difficult to know the cause of hydronephrosis resulting from ureteral polyps before operation by radiological investigations due to the lack of specific diagnostic methods. Retrograde contrast-enhanced angiography and IVP are commonly used in the diagnosis of UFPs. ${ }^{8}$ We can see the filling defects in IVP, which is the characteristic X-ray sign of ureteral polyps, because the polyps move with ureteral peristalsis. This image is called "earthworm peristalsis sign". Two children were diagnosed with this sign preoperation by IVP in our treatment group. Magnetic
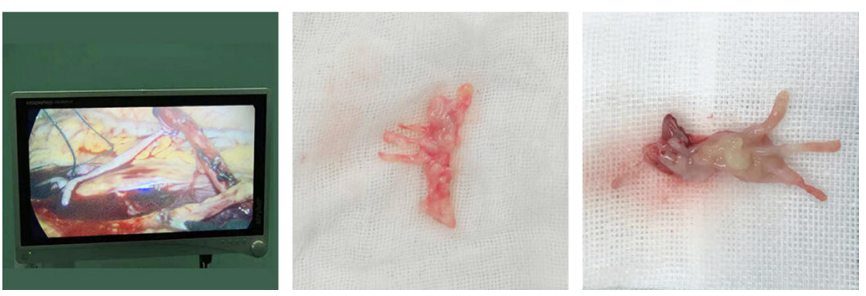

Figure 2 Different types of ureteral fibroepithelial polyps (UFPs). (A) Single polyp. (B) Multiple polyps. (C) Wide-base polyps.
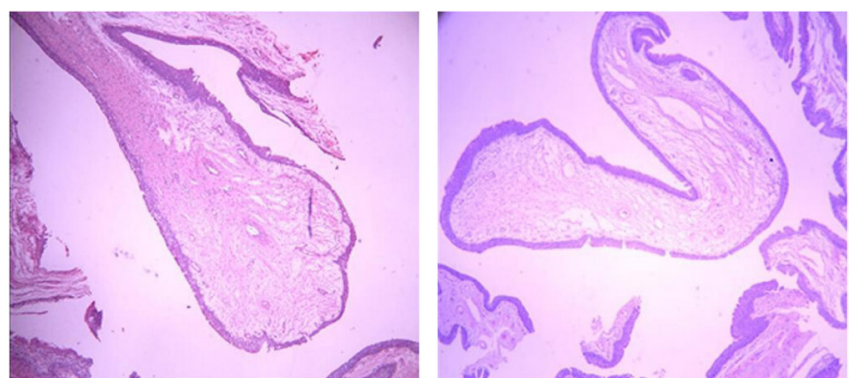

Figure 3 Pathology confirmed primary ureteral fibroepithelial polyp. resonance urography (MRU) is also very helpful in the diagnosis of UFPs. It is less invasive, non-radiating. MRU includes heavily T2-weighted sectional images in orthogonal planes, which allows clear distinction between fluid (bright signal) and tissue (dark signal); the effect should be similar to IVP. All the aforementioned methods to examine polyps need to be identified and diagnosed by experienced doctors.

The treatment of UFPs depends on the location, type (single polyp or multiple polyps) and length of the lesion ureter. Any one of the open, endoscopic, robotic options and laparoscopic method may be available for surgeons to treat UFPs. Open surgery is traumatic and surgical exposure is not superior to that in laparoscopic surgery. Ureteroscopy can be used to diagnose and treat ureteral polyps synchronously and can determine the location, shape and nature of the lesions, making it the preferred treatment. It includes percutaneous antegrade ureteroscope treatment and retrograde ureteroscope treatment. ${ }^{9}$ Cao et at $t^{4}$ used staged antegrade plus retrograde endoscopic laser polypectomy in six adults. After 3 months of follow-up, five cases showed favorable recovery, while one case showed deterioration of hydronephrosis due to ureteropelvic stenosis. Percutaneous antegrade ureteroscope treatment requires the existence of hydronephrosis and the space for operation. For children with intermittent hydronephrosis, this procedure is not appropriate because there is no hydronephrosis during the asymptomatic stage. Moreover, this procedure may cause kidney injury, uncontrolled bleeding and infection. Retrograde ureteroscope treatment with galvanocautery, laser and biopsy forceps had already been used in adults. Georgescu et al proposed that ureteroscopy should be the gold standard diagnostic method as complete polypectomy could be achieved by ureteroscope approach. ${ }^{10}$ Sheng et al treated 25 patients with ureteral polyps by ureteroscopy with holmium (12 cases) or thulium laser (13 cases) resection, which were both considered as effective methods to treat UFPs. Both groups had cases of ureteral stricture, but the thulium method did better in reducing the incidence of ureterostenosis. ${ }^{11}$ Kojima et al reported that they encountered the recurrent UFPs after ureteroscope treatment. ${ }^{12}$ Children's ureters are fine, so laser treatment needs a careful operation, or it may lead 
Table 2 Case series of pediatric ureteral fibroepithelial polyps (since 2003)

\begin{tabular}{|c|c|c|c|c|c|c|}
\hline & Patients (n) & $\begin{array}{l}\text { Incidence of preoperative } \\
\text { diagnosis (\%) }\end{array}$ & Bilateral (n) & Endoscopic & Pyeloplasty & Recurrence \\
\hline Adey et $a^{23}$ & 9 & 25.8 & 2 & $\mathrm{~N}$ & Y & 0 \\
\hline Niu et $a l^{24}$ & 1 & 0 & 0 & $\mathrm{~N}$ & Y & $\mathrm{N} / \mathrm{A}$ \\
\hline Kara et $a l^{25}$ & 5 & 0 & 0 & Y & $\mathrm{N}$ & 0 \\
\hline Kojima et $a^{12}$ & 14 & 21.4 & 0 & Y & $Y^{*}$ & 9 \\
\hline Bian et $a l^{26}$ & 13 & $100 \dagger$ & 2 & N & $Y$ & 0 \\
\hline Arda et $a l^{3}$ & 1 & 0 & 0 & $\mathrm{~N}$ & Y & 0 \\
\hline Cattaneo et $\mathrm{al}^{2}$ & 1 & 100 & 0 & N & Y & 0 \\
\hline Ezekiel et $a l^{27}$ & 1 & 0 & 0 & $\mathrm{~N}$ & Y & 0 \\
\hline Lu et al ${ }^{14}$ & 2 & 100 & 0 & $\mathrm{~N}$ & Y & 0 \\
\hline
\end{tabular}

$\mathrm{N}$ and $\mathrm{Y}$ mean which method the authors chose to deal with UFPs; if they chose endoscopic, it was "Y"; the pyeloplasty line was "N", and the converse was also true.

*Recurrence cases treated with pyeloplasty.

†Endoscopic could diagnose UFPs and then removed them.

N, no; N/A, not applicable; UFP, ureteral fibroepithelial polyp; Y, yes.

to ureteral stricture at a specified future date. For inexperienced doctors, ureteroscopy in children's ureters under limited visual field cannot well determine the number and location of polyps, if the polyps wide base or multiple polyps are prone to have a risk of incomplete polyp treatment, ureterostenosis or ureteral perforation. Therefore, ureteroscope for long ureteral polyps or polys with wide bases is not good, and for ureteral polyps associated with the lesions of intrinsic UPJ, polypectomy alone will not solve the problem. We reviewed case series of pediatric UFPs since 2003 in the English literature (table 2). From the table, we could find that ureteroscopy was helpful in diagnosing UFPs, but the effect of its treatment was not as effective as pyeloplasty. Osbun et al performed robotassisted laparoscopic excision to deal with UFPs in four children. The mean duration of the follow-up was 29 months after the operation. All cases had improved their symptoms and reduced degrees of hydronephrosis. ${ }^{13}$ However, the popularity of robots in Chinese hospitals is not high, and the cost of treatment is high, which is difficult for parents to accept.

Laparoscopic pyeloureteroplasty is a mature surgical method for hydronephrosis. For children with short polyp segment ureter $(<5 \mathrm{~cm})$, this operation may be the first choice of treatment. In this study, the longest ureteral segment of polyps was $3 \mathrm{~cm}$, and after we released the ureter completely, tension-free anastomosis could be performed for all the patients. In our opinion, in the operation of hydronephrosis caused by polyp, the ureter of polyp segment is generally slightly enlarged; the ureter can be transversely cut to expose the polyp first, so as to understand the polyp condition and the length of the polyp segment; the renal pelvis should not be cut too much or not cut, and attention should be paid to protect the blood supply of the ureter when dissociating the ureter, so as to facilitate tension-free anastomosis and postoperative incision healing. Lu et $a l^{14}$ treated 13 cases of obstruction caused by middle ureteral polyp with laparoscopy and ureteral anastomosis. The median follow-up time was 19.1 months, and the patients recovered well. If the ureter of polyp segment is too long $(\geq 5 \mathrm{~cm})$ and if there is tension or failure of anastomosis during the operation, how should we do in the operation? Renal pelvis flap, Bori flap and intestinal flap have been widely used in the treatment of long ureteral defects. The renal pelvis flap is the preferred method to replace the defect of the upper segment of the ureter, blood supply protection should be paid attention to in the design of cutting, the tubular shape should not be distorted, and there should be no tension when ureteral anastomosis was performed. ${ }^{15}$ For the intermittent hydronephrosis caused by ureteral polyp, the dilatation of the renal pelvis is not obvious, so it is necessary to carefully select the pelvis flap to replace the defective ureter. Bori flap is more favorable for the treatment of the lower long ureter defect. Routh $e t a l^{16}$ applied Bori flap laparoscopically to treat the long ureter defect of five children, and the postoperative average follow-up was 3 years. Among them, two had VUR, and the remaining cases recovered well. However, it has been reported that Bori flap can be used to replace the entire ureter. ${ }^{17}$ The replacement of intestinal ureter can replace the length of the ureter defect at any site, but postoperative complications, such as mucous obstruction, urinary calculi, urinary tract infection and electrolyte disturbance, may occur, and the long-term complications are irreversible renal damage, and especially the doublefocus reconstruction may lead to long-term renal deterioration. ${ }^{18}$ At present, ileal replacement of the ureter is considered a mature and effective alternative. ${ }^{19}$ The diameter of the appendix tube in children is close to the ureter, and the peristalsis ability can keep the urine unobtainable; the absorption function is low, and the balance of water and electrolytes will not be disturbed, so it is an ideal choice. Wang et $a t^{20}$ used appendix replacement 
for ureter to treat nine patients with right complicated ureteral stricture, and the average length of ureteral stricture in nine patients was $3.9 \mathrm{~cm}$; the follow-up period was 4-10 months; and the effect was satisfactory. The replacement of the ureter by the appendix is usually applied in the replacement of the right ureteral lesion, while the replacement of the left ureteral defect by the appendix is rare in the literature. When considering the replacement of the left ureteral defect by the appendix, factors such as the length of the appendix mesangium and the position and length of the appendix should be known in advance. ${ }^{21}$ Autogenous kidney transplantation can also be used in the treatment of long ureteral defects, but the surgical technique requires higher requirements. Postoperative complications such as thrombosis, severe urinary tract infection and ureteral necrosis may occur and improper use often requires nephrectomy. ${ }^{22}$

In conclusion, intermittent hydronephrosis associated with abdominal pain occurred in older children, and IVP or magnetic resonance imaging indicated a filling defect in the ureter, highly suggestive of polyp induced hydronephrosis. How to understand the length of polypoid ureteral lesions before surgery still needs to find a better examination method to facilitate the formulation of preoperative surgical plan. The treatment of this hydronephrosis caused by UFPs depends on the location, number, and length of polyps in the affected ureter. If the ureteral segment is short, laparoscopic pyeloureteroplasty is the first choice. For the long segment ureteral defect, individualized treatment should be adopted according to the condition of the child, and urinary system tissue reconstruction should be used as far as possible, followed by intestinal replacement of ureter. With the development of medical technology, artificial ureters that can simulate normal ureter function are constructed in vitro for the repair and reconstruction of long-segment ureteral defects, which are expected to be realized in the future.

Acknowledgements The authors are grateful to the staff at urology department of Anhui Children's Hospital, who were involved in the management of the patients included in the study.

Contributors $\mathrm{CH}$ contributed to writing-original draft. DQF contributed to data curation. CYS contributed to writing-review and editing.

Funding The authors have not declared a specific grant for this research from any funding agency in the public, commercial or not-for-profit sectors.

Competing interests None declared.

Patient consent for publication Not required.

Ethics approval Ethics committee had required review and approval for the article.

Provenance and peer review Not commissioned; externally peer reviewed.

Data availability statement Data are available upon reasonable request. The data in our article are patient related.

Open access This is an open access article distributed in accordance with the Creative Commons Attribution Non Commercial (CC BY-NC 4.0) license, which permits others to distribute, remix, adapt, build upon this work non-commercially, and license their derivative works on different terms, provided the original work is properly cited, appropriate credit is given, any changes made indicated, and the use is non-commercial. See: http://creativecommons.org/licenses/by-nc/4.0/.

\section{REFERENCES}

1 Cai Y, Zhang Z, Yue X. Rare giant primary ureteral polyp: a case report and literature review. Mol Clin Oncol 2017;6:327-30.

2 Cattaneo F, Zattoni F, Meggiato L, et al. Endourologic diagnosis and robotic treatment of a giant Fibroepithelial polyp of the ureter. $J$ Endourol Case Rep 2016;2:172-5.

3 Arda MS, Ilhan $\mathrm{H}$, Kara T, et al. Laparoscopic approach to a rare cause of ureteropelvic junction obstruction in a child: ureteral polyp. European J Pediatr Surg Rep 2015;3:78-81.

4 Cao Y, Chen $\mathrm{Q}$, Zhong $\mathrm{H}$, et al. Treatment of large fibroepithelial polyps in the proximal ureter with antegrade plus retrograde endoscopic laser polypectomy. Medicine 2018;97:e11747.

5 Patel RV, Johal N, Evans K. Antenatal mild hydronephrosis with subsequent polyp of the upper ureter in a child presenting with recurrent Dietl's crisis. BMJ Case Rep 2014:pii: bcr2013202967.

6 Li R, Lightfoot M, Alsyouf M, et al. Diagnosis and management of ureteral fibroepithelial polyps in children: a new treatment algorithm. J Pediatr Urol 2015;11:22.e1-6.

7 Murnaghan GF. The mechanism of congenital hydronephrosis with reference to the factors influencing surgical treatment. Ann $R$ Coll Surg Engl 1958;23:25-46.

8 Akdere H, Çevik G. Rare Fibroepithelial polyp extending along the ureter: a case report. Balkan Med J 2018;35:275-7.

9 Hong P, Cai Y, Li Z, et al. Modified laparoscopic partial ureterectomy for adult ureteral Fibroepithelial polyp: technique and initial experience. Urol Int 2019;102:13-9.

10 Georgescu D, Mulțescu R, Geavlete BF, et al. Fibroepithelial polyps a rare pathology of the upper urinary tract. Rom $J$ Morphol Embryol 2014;55:1325-30.

11 Sheng L, Zhang ZY, Qian WQ, et al. Treatment of ureteral Fibroepithelial polyp by ureteroscopy combined with holmium laser or Thulium laser: a retrospective study. Photomed Laser Surg 2016;34:456-9.

12 Kojima Y, Lambert SM, Steixner BL, et al. Multiple metachronous fibroepithelial polyps in children. J Urol 2011;185:1053-7.

13 Osbun N, Ellison JS, Lendvay TS. Robot-Assisted laparoscopic excision of ureteral and ureteropelvic junction Fibroepithelial polyps in children. J Endourol 2016;30:896-900.

$14 \mathrm{Lu} \mathrm{L}$, Bi Y, Wang X, et al. Laparoscopic resection and end-to-end Ureteroureterostomy for Midureteral obstruction in children. $J$ Laparoendosc Adv Surg Tech A 2017;27:197-202.

15 Xiong SW, Yang KL, Ding GP, et al. [Advances in surgical repair of ureteral injury]. Beijing Da Xue Xue Bao Yi Xue Ban 2019;51:783-9.

16 Routh JC, Tollefson MK, Ashley RA, et al. latrogenic ureteral injury: can adult repair techniques be used on children? J Pediatr Urol 2009;5:53-5.

17 Bansal A, Sinha RJ, Jhanwar A, et al. Laparoscopic ureteral reimplantation with Boari flap for the management of long- segment ureteral defect: a case series with review of the literature. Turk J Urol 2017;43:313-8.

18 Monn MF, Roth JD, Bihrle R, et al. Long term outcomes in the use of ileal ureter for radiation-induced ureteral strictures. Int Urol Nephrol 2018;50:1375-80.

19 Roth JD, Monn MF, Szymanski KM, et al. Ureteral reconstruction with ileum: long-term follow-up of renal function. Urology 2017;104:225-9.

20 Wang J, Xiong S, Fan S, et al. Appendiceal onlay flap Ureteroplasty for the treatment of complex ureteral strictures: initial experience of nine patients. J Endourol 2020;34:874-81.

21 Komyakov BK, Ochelenko VA, Al-Attar TH, et al. [Lower urinary tract urodynamics after reconstruction of the pelvic part of the ureter]. Urologiia 2020;3:10-14.

22 Corbetta JP, Weller S, Bortagaray JI, et al. Ureteral replacement with appendix in pediatric renal transplantation. Pediatr Transplant 2012;16:235-8

23 Adey GS, Vargas SO, Retik AB, et al. Fibroepithelial polyps causing ureteropelvic junction obstruction in children. $J$ Urol 2003;169:1834-6.

24 Niu ZB, Yang Y, Hou Y, et al. Ureteral polyps: an etiological factor of hydronephrosis in children that should not be ignored. Pediatr Surg Int 2007;23:323-6.

25 Kara C, Reșorlu B, Oğuz U, et al. Incidentally detected ureteral fibroepithelial polyps in children: is endoscopic treatment of them really necessary? Int Urol Nephrol 2010;42:1-5.

26 Bian Z, Liu X, Hua Y, et al. Laparoscopic management of multiple ureteral polyps in children. J Urol 2011;186:1444-9.

27 Ezekiel A, Agrawal V, Romero E, et al. Benign Fibroepithelia polyps: a rare cause of ureteropelvic junction obstruction in children. Urol Case Rep 2015;3:111-3. 